Western University

Scholarship@Western

Brescia School of Behavioural \& Social

Sciences Publications

School of Behavioural \& Social Sciences

2019

\title{
Individual Differences in Cognitive Map Accuracy: Investigating the Role of Landmark Familiarity
}

Nicole L. Youngson

The University of Western Ontario

Megan Vollebregt

Western University

Jennifer Sutton

Brescia University College, jsutton7@uwo.ca

Follow this and additional works at: https://ir.lib.uwo.ca/bresciabehaviouralsocialsciencespub

Part of the Psychology Commons

Citation of this paper:

Youngson, Nicole L.; Vollebregt, Megan; and Sutton, Jennifer, "Individual Differences in Cognitive Map Accuracy: Investigating the Role of Landmark Familiarity" (2019). Brescia School of Behavioural \& Social Sciences Publications. 1.

https://ir.lib.uwo.ca/bresciabehaviouralsocialsciencespub/1 


\title{
Individual Differences in Cognitive Map Accuracy: Investigating the Role of Landmark Familiarity
}

\author{
Nicole L. Youngson \\ Brescia University College
}

\author{
Meghan Vollebregt \\ Western University
}

\author{
Jennifer E. Sutton \\ Brescia University College and Western University
}

\begin{abstract}
Broad individual differences exist in the ability to create a cognitive map of a new environment. The current studies investigated whether familiarizing participants with to-be-learned target landmarks (Experiment 1) or target landmarks plus the order they would be encountered along routes (Experiment 2) before exploring the Silcton virtual environment would increase performance on tasks assaying spatial memory of Silcton. Participants in both experiments were randomly assigned to be pre-exposed either to information about target landmarks in Silcton or control landmarks on the university campus. In both experiments, participants explored Silcton via four prescribed routes and then performed a direction estimation task and a map building task based on memory for the locations of the target landmarks. In addition, participants completed the Spatial Orientation Test of perspective-taking. Pre-exposure to Silcton landmarks versus control landmarks did not affect scores on Silcton-based tasks in either experiment. Some sex differences in direction estimation were observed in Experiment 1 but not Experiment 2. While facilitating familiarity with landmarks did not improve cognitive map accuracy, both sex and perspective taking ability were found to contribute to individual differences in the ability to create a cognitive map.
\end{abstract}

Public Significance Statement

Individual differences in the ability to create a mental map of a novel environment have been demonstrated in the laboratory, but their origins are not well understood. It is possible that familiarizing individuals with the buildings and the routes in a new environment before they experience it may help them form a mental map. Such pretraining did not facilitate the accuracy of mental representations, and it seems likely that variation in spatial visualization abilities is a larger contributor to individual differences in mental map accuracy.

Keywords: spatial cognition, navigation, cognitive map

Navigation is a multifaceted skill that involves the coordination of numerous cognitive processes that rely on a combination of environmental and self-motion cues, mental transformations of space, executive processes, and spatial representations that include "online" information such as current progress along a route and "offline" representations, such as the layout of landmarks stored in memory (Wolbers \& Hegarty, 2010). The cognitive map is a particularly powerful type of mental representation because it enables a navigator to take detours, novel routes, and short-cuts (O'Keefe \& Nadel, 1978; Tolman, 1948). While there is some controversy about the utility of cognitive maps and whether they exist (Bennett, 1996; Chrastil \& Warren, 2014), recent evidence suggests that cognitive maps do exist for some individuals but not for others (Ishikawa \& Montello, 2006; Weisberg \& Newcombe, 2016; Weisberg, Schinazi, Newcombe, Shipley, \& Epstein, 2014).
Nicole L. Youngson, School of Behavioural and Social Sciences, Brescia University College; Meghan Vollebregt, Department of Psychology, Western University; Jennifer E. Sutton, School of Behavioural and Social Sciences, Brescia University College, and Department of Psychology, Western University.

Nicole L. Youngson is now at the Faculty of Education, Western University. Meghan Vollebregt is now at the School of Communication Sciences and Disorders, Western University.
This research was supported by a grant from the Natural Sciences and Engineering Research Council of Canada to Jennifer E. Sutton. We thank Chantelle Cocquyt for assistance testing subjects. Data reported here are archived at https://osf.io/kjz9b/.

Correspondence concerning this article should be addressed to Jennifer E. Sutton, School of Behavioural and Social Sciences, Brescia University College, London, ON N6G 1H2, Canada. E-mail: jennifer .sutton@uwo.ca 
Two theoretical proposals attempt to describe how humans create a cognitive map of a novel environment. In the earlier of these, Siegel and White (1975) suggested that cognitive map acquisition occurs in steps. They proposed that the first step in the process was to identify and learn the names of landmarks. Landmarks can be thought of as distinctive features of an environment that act as associative cues for the navigator (Montello, 1998; Siegel \& White, 1975; Waller \& Lippa, 2007). The second step involved learning and remembering routes, consisting of remembering the sequence of landmarks, the direction to take after encountering each landmark, and rough estimates of distance (Montello, 1998; Siegel \& White, 1975; Waller \& Lippa, 2007). In the final step, Siegel and White (1975) proposed that the accumulation of route knowledge formed the foundation for a cognitive map representation, which was created by integrating separate routes into a single map. Later, Montello (1998) argued that cognitive maps were not necessarily formed in steps but instead both route and map knowledge of the environment could begin upon first exposure to the novel environment. Furthermore, he emphasized that knowledge acquisition could occur at different rates for different individuals, despite having the same amount of exposure. In particular, he argued that individual differences would be especially prominent for the ability of an individual to integrate routes into a cognitive map.

Evidence that supports aspects of both the Siegel and White (1975) and Montello (1998) proposals comes from studies requiring participants to learn the layout of an environment via specific, predetermined routes that must be integrated to form a cognitive map. Support for Montello's argument against strict stages during learning and individual differences in cognitive map accuracy was provided by Ishikawa and Montello (2006). Participants were driven in an unfamiliar environment once a week for 10 weeks where they learned the locations of landmarks on two separate routes, followed later by driving along a connecting route. Participants' ability to integrate the routes into a single mental map was measured by their accuracy estimating the directions between landmarks and drawing a map of the entire area. Performance on these tasks revealed broad individual differences in the ability to form a mental cognitive map of the environment. In addition, data showed some people were able to form a cognitive map early in testing, and those who performed well or poorly at the beginning of the study tended to perform similarly over the 10 weeks. More recently, Weisberg et al. (2014) also demonstrated individual differences in cognitive map accuracy based on travelling along routes in a virtual environment, Silcton. In this single-session study, participants attempted to learn the locations of eight landmarks along two separate main routes and then travelled along two connector routes that linked the main routes together. Cognitive map accuracy was assessed via direction estimation between the landmarks and arranging the landmarks on a blank map of Silcton. As in Ishikawa and Montello's study, participants' performance ranged from highly accurate to nearly chance performance. Taken together, the studies provide strong evidence that there are individual differences in the ability to create a cognitive map of a new space by integrating separate routes, and that some people can do this quite quickly.

There is also recent indirect evidence to support aspects of Siegel and White's (1975) theory, however, especially if the stages of learning they proposed are considered a hierarchy, as their ordered sequence implies. In such a hierarchy, landmark identities would be at the bottom, routes would be in the middle, and a full cognitive map would be at the top. Each level of knowledge would include all levels below it, so route knowledge would include landmark identities and cognitive maps would include knowledge of both routes and landmark identities. Such a hierarchy has been supported by studies that classified individuals according to the accuracy of their cognitive map and route knowledge of Silcton in assessments of direction estimation between landmarks on the same route (route knowledge) and across different routes (cognitive map knowledge; Weisberg et al., 2014; Weisberg \& Newcombe, 2016). For instance, Weisberg et al. found that participants showed either strong map and strong route knowledge, weak map but strong route knowledge, or both weak map and weak route knowledge. Critically, and exactly as Siegel and White's ordered sequence would predict, virtually no one showed strong route knowledge with weak map knowledge. Weisberg and Newcombe replicated this finding and also found that better recall of the names and appearances of Silcton landmarks was associated with both better route memory and more accurate cognitive maps. While these studies were not motivated by a test of the ordered sequence of knowledge proposed by Siegel and White per se, their results nonetheless suggest that a pattern of route and map knowledge acquisition exists.

In the studies reported here, we tested the order of spatial knowledge acquisition suggested by Siegel and White (1975) more directly using the Silcton virtual environment. Specifically, we were interested in whether giving some participants a "head start" on learning the layout of Silcton with information from the first steps in Siegel and White's sequence would facilitate the accuracy of the cognitive maps they created of Silcton. It could be that a significant portion of participants might eventually form an accurate cognitive map of Silcton but fail to because they do not quickly acquire the foundational knowledge of landmark identities and their ordering along routes. Indeed, Weisberg and Newcombe (2016) suggested that weak nonspatial associative memory could be impeding some individuals' ability to form an accurate cognitive map of Silcton. If a failure to progress through the early steps in Siegel and White's theory is impeding the ability of some participants to create a cognitive map, extra information provided before exploring the environment should result in more accurate mental map representations.

We provided the "head start" by pre-exposing some participants to aspects of Silcton before they explored the environment. In Experiment 1, participants in the experimental group were preexposed to the target building appearances and names from Silcton (corresponding to the first step in Siegel \& White, 1975), and in Experiment 2, the experimental group was pre-exposed to both the building names and appearances and their ordering along the two main routes in Silcton (the first and second step in Siegel \& White). A control group in each study was pre-exposed to unfamiliar buildings and routes on the local campus that were unrelated to Silcton. Our main prediction across both studies was that participants in the experimental groups who were pre-exposed to information about Silcton would show more accurate direction estimation and map building performance based on memory for Silcton than those in the control groups. We were also interested in whether pre-exposure condition would interact with sex, given that sex differences are sometimes shown in Silcton (Weisberg \& 
Newcombe, 2016). In addition to the pre-exposure manipulation, all participants completed the Spatial Orientation Test (SOT; Hegarty \& Waller, 2004) of spatial perspective-taking, which we did not predict would be affected by the pre-exposure manipulation, but has been shown in other work to be associated with cognitive map accuracy (Fields \& Shelton, 2006; Kozhevnikov, Motes, Rasch, \& Blajenkova, 2006; Schinazi, Nardi, Newcombe, Shipley, \& Epstein, 2013; Weisberg et al., 2014).

\section{Experiment 1}

In Experiment 1, we tested the idea that pre-exposure to Silcton building/name pairs, corresponding to Siegel and White's (1975) first step in spatial knowledge acquisition, would facilitate the creation of more accurate cognitive maps of Silcton. Participants were randomly assigned to a Silcton building pre-exposure group or a control group that was pre-exposed to obscure buildings and their names on the Western University campus. As in previous work (Hegarty, Montello, Richardson, Ishikawa, \& Lovelace, 2006; Ishikawa \& Montello, 2006; Weisberg et al., 2014), cognitive map accuracy was assessed using direction estimation and map creation. Our main hypothesis was that pre-exposure to Silcton buildings would help facilitate learning the layout of Silcton, so that individuals who received the Silcton building pre-exposure memory association task should perform better on the cognitive map assessments than those in the control group.

\section{Method}

Participants. Participants were 80 undergraduate students (40 male and 40 female) in introduction to psychology at Brescia University College and Western University. Their ages ranged from 17 to 31 years old $(M=19.03, S D=2.08)$. Participants were randomly assigned to either the Silcton pre-exposure group or the control group, with equal numbers of males and females in each group. All participants received course credit for participating, and all procedures were approved by the Non-Medical Research Ethics Board at Western University.

Materials. Participants first provided demographic information (age, sex) on a short questionnaire. The virtual environment and associated tasks were administered on one of two computers: an Asus Transformer Book laptop with a 15.6" screen and an Intel Graphics 440 video card, or a Toshiba Satellite Pro laptop with a 15.6" screen and an NVIDIA GeForce video card. Participants travelled through a web-based virtual environment, Silcton (Weisberg et al., 2014). The layout of Silcton is asymmetrical (i.e., not a city grid) and contains buildings and other features such as trees, mailboxes, benches, and so forth (see Figure 1 for a map of Silcton). The accuracy of participants' cognitive maps was measured using two tasks included with the Silcton software: direction estimation (called Offsite Pointing in Silcton software) and map building (called Model Building in Silcton).

Santa Barbara Sense of Direction Scale (SBSOD; Hegarty, Richardson, Montello, Lovelace, \& Subbiah, 2002). The SBSOD scale is a self-report measure of navigation ability. The questionnaire was administered on the computer and consists of 15 items on a 7-point Likert scale with 1 indicating strong agreement with the item and 7 indicating low agreement with the item. Sample items include "I am very good at judging directions" and
"I am very good at reading maps". For our analysis, we reversed the scale for all items such so that higher scores would correspond to better self-reported navigation ability.

Spatial Orientation Task (SOT; Hegarty \& Waller, 2004; Kozhevnikov \& Hegarty, 2001). The version of the SOT used in this study was developed by Hegarty and Waller (2004). In this pencil-and-paper task, participants viewed an arrangement of objects on the top half of the page and were asked to imagine that they were standing at one of those objects facing a second object and to imagine the direction of a third object. The direction of the third object was indicated by drawing a line in a circle located on the bottom half of the page. Participants were allowed $5 \mathrm{~min}$ to complete as many of the 12 items as possible. An error score for each participant was calculated by first determining the absolute difference between the correct angle and the participant's drawn angle for each completed item and the averaging over items to calculate an overall error score

Pre-exposure memory tasks. Participants were randomly assigned to either the Silcton pre-exposure group or the control group. In the Silcton pre-exposure group, 40 participants (20 females) viewed a sequence of slides in Microsoft PowerPoint with each slide showing an image of one of the eight target buildings in Silcton along with its name. Participants were instructed to look at each slide and try to become familiar with the building and its name and were given as much time as they needed. At the end of the slide show, participants were given a matching task where they were presented with the eight building images and the eight building names and were instructed to drag and drop the correct name under each building image. If any of the eight matches were incorrect, participants were asked to view the slide show again and attempt the memory task again. This study-test sequence was repeated until the subject was successful at matching all eight names to the correct building images.

The 40 participants ( 20 females) in the control group completed the same tasks as the Silcton pre-exposure group, however the building images were obscure buildings from the local campus that the participants were unlikely to be familiar with. As with the Silcton pre-exposure task, the study-test phases were completed until all buildings were successfully matched with their names.

Silcton Route Exploration Task. Prior to exploring the routes in Silcton, participants practiced moving in the virtual environment by using the computer arrow keys and mouse pad to walk around a central statue in Silcton. Once comfortable with the controls, participants were instructed that they would travel along four different routes in Silcton by following red arrows on the ground (see Figure 1 for a map of Silcton and the four routes) and to try to remember the locations of four target buildings on each route marked with a distinct floating diamond. First, participants travelled from the start of route A until the end and then back to the start and were given as much time as needed. Next, they travelled along Route B the same way. After routes A and B, which did not overlap at any point, had been explored, participants travelled along routes $\mathrm{C}$ and $\mathrm{D}$, each of which connected different points of routes A and B. Participants were given the same unlimited time to travel each connecting route from start to finish and then back to start.

Direction Estimation Practice Task. Immediately after exploring the Silcton routes, participants were familiarized with the direction estimation task using six familiar buildings from the 


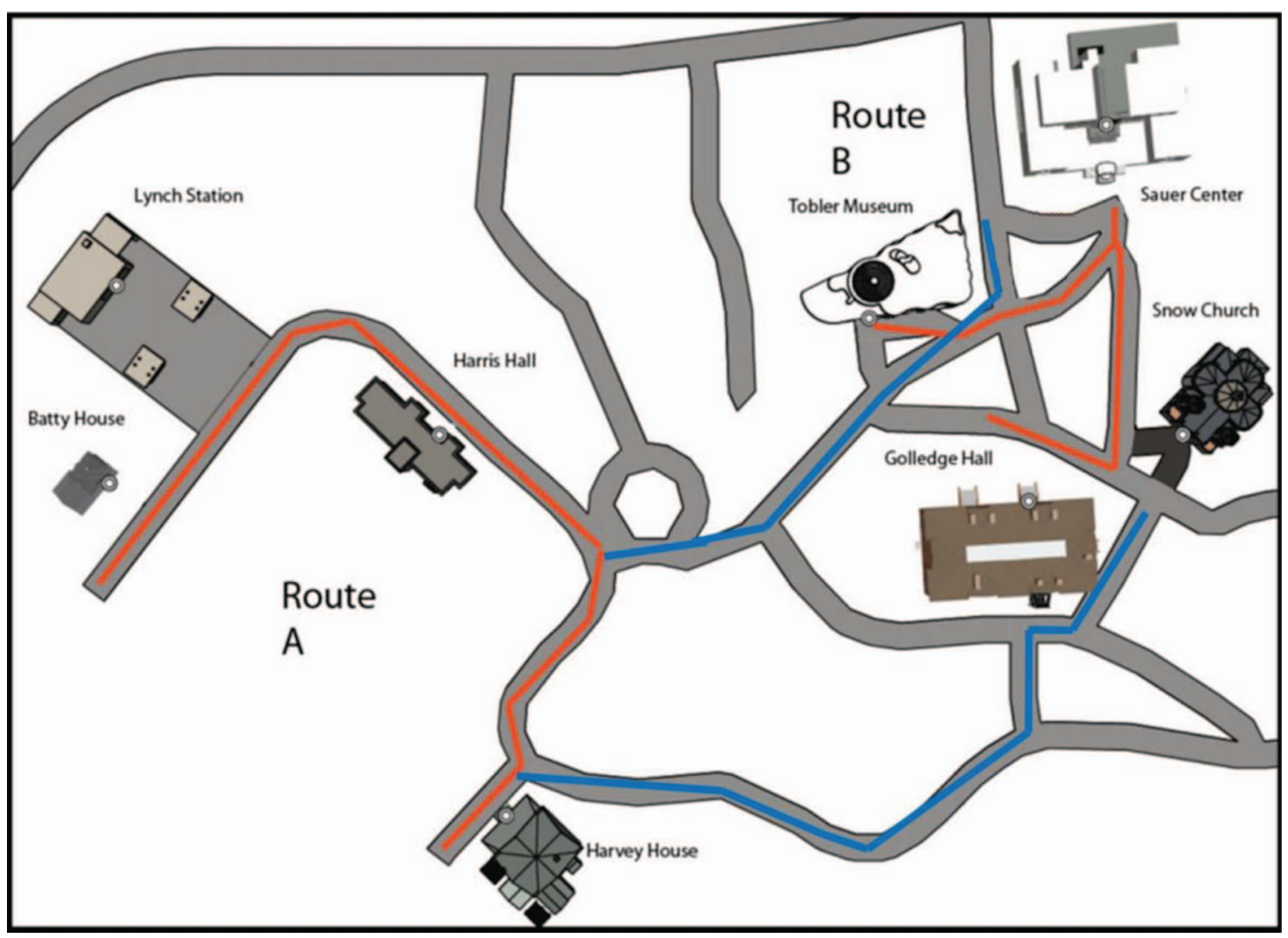

Figure 1. Overhead view of the Silcton environment including the two main routes A (in red or lighter gray that connects Batty House, Lynch Station, Harris Hall, and Harvey House) and B (in red or lighter gray that connects Tobler Museum, Sauer Center, Snow Church, and Golledge Hall) and the two connector routes (in blue or darker gray). From "Variations in Cognitive Maps: Understanding Individual Differences in Navigation," by S. M. Weisberg, V. R. Schinazi, N. S. Newcombe, T. F. Shipley, and R. A. Epstein, 2014, Journal of Experimental Psychology: Learning, Memory, and Cognition, 40, 671. Copyright 2013 by the American Psychological Association. Adapted with permission. See the online article for the color version of this figure.

Western University campus (all different from the buildings studied by the Control group) presented in PowerPoint. On each of the four trials, participants were instructed to imagine they were standing at one building, shown in the center of a blank circle, facing another campus building shown at the top of the circle. They then dragged pictures of the four remaining buildings into their correct locations on the circle relative to the assumed heading. Participants completed this task 4 times with different buildings in the center and at the top of the circle and were encouraged to talk aloud, point with their arms, and look out the window to complete the task. At the end of every trial, the experimenter showed and discussed with the participant the correct placement by dragging and dropping the buildings to their correct location on the circle's edge if not already placed there.

Silcton Direction Estimation Task. After the direction estimation practice task, the Silcton direction estimation task contained in the software package of Silcton applications began and was also administered on the laptop. On each trial, participants were presented with the outline of a circle on the screen with one Silcton building name in the center and a second Silcton building name at the top of the circle. They were first instructed to imagine they were standing at the center building facing the top building. Next, they were instructed to place the names of the remaining 6 target buildings along the circle at the correct angle relative to the imagined heading. They completed 8 trials, 4 with a starting building and a facing building on Route A and 4 with starting and facing buildings on Route B. Participants were instructed to move the remaining buildings into position on the circle at the correct locations relative to the established heading. They estimated the directions to buildings both on the same route as those forming the heading and on a different route, resulting in measures of mean error within routes and mean error between routes for each participant. We chose to use this "offsite pointing" task from Silcton instead of the more commonly used "onsite pointing" task (e.g., Weisberg et al., 2014). In onsite pointing, participants are placed back in the environment to estimate directions. This onsite version contains some trials where the target building (i.e., the to-bepointed-to building) was visible from the location where the participant was standing. Therefore, the onsite task does not strictly depend on the representation of Silcton held in memory and potentially provides additional information about Silcton after the exploration period. For these reasons, we used the offsite version of the task in the experiments reported here.

Silcton Map Building Task (Weisberg et al., 2014). In the map building task, participants were presented with a blank rect- 
angle on the screen and overhead views of the eight Silcton buildings outside the rectangle along the bottom of the screen. They were instructed to place the eight buildings in the box to create an accurate aerial view of Silcton. Accuracy was calculated by the Silcton software using bidimensional regression that compared the accuracy of the participant's map to the actual map and produced an $R^{2}$ value.

Route Ordering Task. In the pencil-and-paper route task, participants were asked to place the buildings of the two main routes, $\mathrm{A}$ and $\mathrm{B}$, in the correct order. For each route, the first and last building was shown, and the participants' task was to indicate the other two target buildings in order along the route. Participants were provided with a list of all eight buildings and their names when completing each route. The order of presentation of the two routes was counterbalanced across participants. Accuracy was calculated as a correlation between the participant's ordering and the correct route ordering using Kendall's tau.

Procedure. After obtaining written informed consent, participants completed the demographic questionnaire, the SBSOD scale, and the SOT. After the SOT, participants completed their assigned pre-exposure task (either Silcton buildings or control buildings). Once in the Silcton virtual environment, participants practiced using the computer controls and then explored Silcton via routes $\mathrm{A}, \mathrm{B}, \mathrm{C}$, and $\mathrm{D}$. The remaining tasks were completed outside the Silcton virtual environment. Participants were first given the direction estimation practice task before being asked to complete the Silcton direction estimation task. Next, they completed the Silcton map building task and finally the route ordering task. The entire testing session took approximately $60 \mathrm{~min}$.

\section{Results}

Tests of the pre-exposure effect. We first investigated whether performance on the four Silcton dependent measures (map building, different-route direction estimation, same-route direction estimation, and route ordering) was influenced by pre-exposure group (2: Silcton buildings, campus buildings) and/or sex (2: male, female) using a multivariate analysis of variance (MANOVA). Means and standard deviations for all measures are presented in Table 1. In the initial multivariate analysis using Pillai's trace, there was no main effect of group, $V=.08, F(4,73)=1.50, p=$
$.21, \eta_{\mathrm{p}}^{2}=.08$, nor a Group $\times$ Sex interaction, $V=.03, F(4,73)=$ $0.48, p=.75, \eta_{\mathrm{p}}^{2}=.03$, but there was a significant main effect of sex, $V=.22, F(4,73)=5.08, p=.001, \eta_{\mathrm{p}}^{2}=.22$. Follow-up univariate analyses of the significant sex main effect for each dependent measure revealed a significant main effect of sex for the map building measure, $F(1,76)=10.80, p=.002, \eta_{\mathrm{p}}^{2}=.12$, and different-route direction estimation, $F(1,76)=13.30, p<.001$, $\eta_{\mathrm{p}}^{2}=.15$, indicating better performance by men on both tasks. There was no main effect of sex on the route ordering task, $F(1$, 76) $=2.29, p=.13, \eta_{\mathrm{p}}^{2}=.03$, and no main effect for same-route direction estimation, $F(1,76)=2.24, p=.14, \eta_{\mathrm{p}}^{2}=.03$, indicating no evidence for a difference between men and women on those tasks.

In addition, a Bayesian Group $\times$ Sex ANOVA for each Silcton dependent measure was conducted in JASP (JASP Team, 2018) using default priors in order to allow a fuller interpretation of the effects (and lack thereof) seen in the MANOVA by comparing the likelihood of the data under the null and alternative hypotheses for each effect. For different-route direction estimation, the Bayes factor (null/alternative, $\mathrm{BF}_{01}$ ) showed the data were 1.01:1 in favor of the null hypothesis of no effect of group, or 1.01 times more likely to occur in a model with no group differences than one with group differences, $\mathrm{BF}_{01}=1.01$. For the effect of sex, data were 0.02:1 in favor of the alternative hypothesis, or 50 times more likely to occur in a model with sex differences, $\mathrm{BF}_{\mathrm{O} 1}=.02$. For the interaction effect, the data were 3.15:1 in favor of the null hypothesis of no interaction, $\mathrm{BF}_{01}=3.15$. For the other measure of cognitive map accuracy, model building, the data were $1.37: 1$ in favor of the null hypothesis of no differences based on group, $\mathrm{BF}_{01}=1.37$, but $.054: 1$ in favor of the alternative hypothesis of sex differences (18 times more likely under a model with sex differences than no sex differences), $\mathrm{BF}_{01}=.054$. For the Group $\times$ Sex interaction, data were 1.78:1 in favor of the null hypothesis versus a model with the interaction, $\mathrm{BF}_{01}=1.78$. For the same-route direction estimation measure, the observed data were 2.81:1 in favor of the null versus a model with group differences, $\mathrm{BF}_{01}=1.78,1.61: 1$ in favor of the null versus a model with sex differences, $\mathrm{BF}_{01}=1.61$, and $3.32: 1$ in favor of the null versus a model with a Group $\times$ Sex interaction, $\mathrm{BF}_{01}=$ 3.32. Finally, the route ordering data were 4.02:1 in favor of the

Table 1

Means and Standard Deviations on Silcton Measures for Both Pre-Exposure Groups in Experiment 1

\begin{tabular}{lcccc}
\hline $\begin{array}{c}\text { Pre-exposure } \\
\text { group }\end{array}$ & Map building ${ }^{\mathrm{a}}$ & $\begin{array}{c}\text { Direction estimation }^{\mathrm{b}} \text { : } \\
\text { different routes }\end{array}$ & $\begin{array}{c}\text { Direction estimation } \\
\text { same routes }\end{array}$ & Route ordering $^{\mathrm{c}}$ \\
\hline $\begin{array}{l}\text { Silcton buildings } \\
\text { Males }\end{array}$ & $.45(.29)$ & $81.54(12.07)$ & $61.81(7.56)$ & $.87(.18)$ \\
$\quad$ Females & $.34(.19)$ & $91.34(10.24)$ & $64.94(9.82)$ & $.77(.31)$ \\
$\quad$ Total & $.39(.25)$ & $86.44(12.11)$ & $63.38(8.79)$ & $.82(.26)$ \\
Control buildings & & & & \\
$\quad$ Males & $.61(.23)$ & $77.01(14.15)$ & $60.29(7.19)$ & $.89(.23)$ \\
Females & $.36(.24)$ & $85.83(8.42)$ & $62.76(8.60)$ & $.81(.30)$ \\
$\quad$ Total & $.49(.26)$ & $81.42(12.33)$ & $61.53(7.92)$ & $.85(.27)$ \\
All males & $.53(.27)$ & $79.27(13.18)$ & $61.05(7.31)$ & $.88(.20)$ \\
All females & $.35(.22)$ & $88.58(9.67)$ & $63.85(9.17)$ & $.79(.31)$ \\
\hline
\end{tabular}

Note. Standard deviations are in parentheses.

${ }^{\mathrm{a}} R^{2}$ values. ${ }^{\mathrm{b}}$ Absolute error in degrees. ' ${ }^{\mathrm{c}}$ Kendall's Tau. 
null model versus a model with an effect of group, $\mathrm{BF}_{01}=4.02$, 1.56:1 in favor of the null model versus a model with an effect of sex, $\mathrm{BF}_{01}=1.56$, and 2.99:1 in favor of a null model versus a model with a Group $\times$ Sex interaction, $\mathrm{BF}_{\mathrm{O} 1}=2.99$. Therefore, the Bayesian statistics suggest strong support for a model with a main effect of sex differences on the cognitive map measures and anecdotal to substantial support for the null model for all other effects.

Correlations between dependent measures. Next, we conducted two-tailed Pearson correlations to assess the interrelatedness of the four Silcton dependent measures in our sample, plus scores on the SBSOD and SOT, and sex. As can be seen in Table 2 , the Silcton measures that are believed to rely on map-like knowledge, map building, and different-route direction estimation were significantly correlated such that better map building accuracy was associated with lower direction estimation error between landmarks on different routes. The two Silcton measures that are presumed to rely on route knowledge, route ordering, and sameroute direction estimation were not correlated, however. In addition, same-route direction estimation was not significantly related to any other dependent measure in the study. The route-ordering measure was positively correlated with map building, indicating that better memory for the order of items along each route was associated with building a more accurate map. The Silcton measure that was significantly associated with participants' selfreported navigation abilities on the SBSOD was map building. Finally, we confirmed that the overall mean error values for same-route direction estimation and different-route direction estimation were significantly different from chance $\left(90^{\circ}\right)$, same route: $t(79)=29.45, p<.001$, different route: $t(79)=4.38, p<.001$.

Table 2 also shows that better performance on the SOT measure of perspective-taking ability was significantly associated with better map building accuracy and better route ordering accuracy (since SOT produces a measure of error, both of these correlations are negative). The SOT was also significantly and positively correlated with sex, indicating that better performance on the SOT (i.e., lower error) was associated with being male (males were coded as 1 and females as 2 in this analysis).

Sex versus perspective taking for map building performance. The significant correlations between SOT and sex and between SOT and Silcton map building raise the possibility that the sex differences seen in the MANOVA for map building may instead be wholly or partially due to perspective-taking differences instead. In order to discern the relative importance of perspective taking and sex, we conducted a hierarchical regression analysis using sex and
SOT performance as predictors and map building as the outcome. Sex was entered into the model in the first step and was a significant predictor, $\beta=-.34, p=.002$, with the model after this step accounting for a significant proportion of variance in map building, $R^{2}=.12, F(1,78)=10.47, p=.002$. SOT score was added as a predictor in the second step and was also a significant predictor, $\beta=-.25, p=.03$, although the predictive value of sex was reduced to being marginally significant once SOT was added to the model, $\beta=-.24, p=.045$. The second and final model accounted for a significant proportion of the variance in map building, $R^{2}=.17, F(2,77)=7.90, p=.001$, and was a significant improvement over the first model, $\Delta R^{2}=.05, \Delta F(1$, $77)=4.82, p=.03$. Therefore, for map building, perspective taking was a slightly better predictor of performance than sex.

\section{Discussion}

Pre-exposing participants to landmarks found in the Silcton virtual environment did not significantly affect performance on any of the tasks used to measure the accuracy of cognitive maps or routes of Silcton. There were some sex differences in performance, however, in that males outperformed females on the SOT and one of the Silcton cognitive map tasks but not on tasks that assayed knowledge of Silcton routes. These results suggest that there is no evidence that pre-exposure to landmark identities facilitates building a cognitive map of a novel virtual environment.

There are some important limitations to the interpretation of these data, however. With a total sample of 80 , power to detect a medium between-subjects effect in the univariate ANOVAs was only about .59 as calculated post hoc using $G^{*}$ Power 3.1 (Faul, Erdfelder, Lang, \& Buchner, 2007). Furthermore, any facilitative effect of Silcton pre-exposure may have helped only a small number of people and therefore be undetectable with the current sample size, and/or it may not have been robust enough to affect performance in the virtual environment. In Experiment 2, we addressed these issues by increasing both the sample size and the amount of information during pre-exposure.

\section{Experiment 2}

In Experiment 2, we addressed two shortcomings of Experiment 1. First, we recruited and tested a larger sample $(N=122)$. Next, we increased the pre-exposure information experienced by the experimental group so that it consisted not only of Silcton building names and appearances but also the order of the buildings along

Table 2

Means, Standard Deviations, and Pearson Correlations for Silcton and Non-Silcton Measures in Experiment 1

\begin{tabular}{|c|c|c|c|c|c|c|c|c|}
\hline Measure & Sex & SBSOD & SOT & $\underset{\text { building }}{\text { Map }}$ & $\begin{array}{c}\text { Route } \\
\text { ordering }\end{array}$ & $\begin{array}{l}\text { Direction estimation: } \\
\text { different routes }\end{array}$ & $M$ & $S D$ \\
\hline SBSOD & -.15 & - & - & - & - & - & 4.05 & 1.02 \\
\hline SOT & $43^{* * * * *}$ & -.13 & - & - & - & - & 39.68 & 25.96 \\
\hline Map building & $-.34^{* *}$ & $.27^{*}$ & $-.35^{* * *}$ & - & - & - & .44 & .26 \\
\hline Route ordering & -.17 & .05 & $-.28^{*}$ & $.23^{*}$ & - & - & .83 & .26 \\
\hline Direction estimation: different routes & $.39^{* * *}$ & -.16 & .18 & $-.39^{* * * *}$ & -.16 & - & 83.93 & 12.40 \\
\hline Direction estimation: same route & .17 & .18 & .11 & -.18 & -.16 & .05 & 62.45 & 8.37 \\
\hline
\end{tabular}

Note. $\quad N=80$. SBSOD $=$ Santa Barbara Sense of Direction Scale; SOT $=$ Spatial Orientation Test.

${ }^{*} p<.05 . \quad{ }^{* * *} p<.01 .^{* * * *} p<.001$. 
each main route. Therefore, participants in the experimental group were pre-exposed to aspects of the first two steps of Siegel and White's (1975) sequence of spatial knowledge acquisition. Put in terms of a hierarchy of spatial knowledge, the experimental condition in Experiment 2 was exposed to even more information that forms the foundation upon which a cognitive map representation can be built. Participants in the control condition again participated in an identical pre-exposure task except the buildings used were obscure campus buildings and routes between them.

\section{Method}

Participants. An a priori power analysis in $\mathrm{G}^{*}$ Power 3.1 (Faul et al., 2007) suggested that 128 participants were required to detect a medium effect with a power value of .80 . We tested 122 members of the campus community who were recruited via advertisements and the introduction to psychology research participation pool. There were 62 males and 60 females with ages ranging from 17 to 64 years old $(M=23.20, S D=7.74)$. Participants were randomly assigned to either the Silcton pre-exposure group (30 males and 31 females) or the control group (32 males and 29 females).

Materials and procedure. All materials and the procedure were the same as in Experiment 1 except a new task to train participants on the order of landmarks along two routes was added to the pre-exposure phase for both groups. Once participants had correctly answered all the items on the pre-exposure building identity matching task (the same task as in Experiment 1), they moved on to the landmark ordering task using another set of PowerPoint slides. Participants in the Silcton pre-exposure group were told that now the buildings would be divided into two routes and they would need to learn the order of the buildings on each route. The first slide showed pictures of the Route A buildings with their names in the order they would be encountered on the initial journey along the route (1 Batty House, 2 Lynch Station, 3 Harris Hall, 4 Harvey House), then each building picture and name was shown on its own slide in order of appearance on the route. The final training slide for route A was the same as the first, with all four buildings shown in order. Next, participants saw similar slides for the buildings along route B (Golledge Hall, Snow Church, Sauer Centre, and Tobler Museum). Finally, they were presented with a slide that showed all eight buildings, and their task was to pick the four buildings from route $\mathrm{A}$ and drag and drop them onto a line with first, second, third, and fourth position indicated along the route at the bottom of the slide. The final slide was identical to the previous slide except the task was to pick and order the buildings for route B. If the buildings for both routes A and B were correctly ordered, participants moved on to the Silcton exploration task. For any incorrect responses, the experimenter showed the participant the correct response and the participant started again from the beginning of the route ordering slideshow and again completed the ordering task at the end. This continued until the buildings on both routes were placed in their correct position in order, and then the participant moved on to Silcton exploration. The control group completed the same tasks as the Silcton group and met the same criterion (error-free ordering of both routes) before moving on to the Silcton exploration task, except the buildings and routes were made up of the eight campus buildings.

\section{Results}

As in Experiment 1, we first conducted tests to determine whether the pre-exposure manipulation had an effect on dependent measures based on memory for Silcton. Next, we investigated the intercorrelations of the dependent measures.

Tests of the pre-exposure effect. Using MANOVA, we investigated whether performance on the four Silcton dependent measures (map building, different-route direction estimation, same-route direction estimation, and route ordering) was influenced by pre-exposure group (2: Silcton buildings, campus buildings) and/or sex (2: male, female). Means and standard deviations for all measures are presented in Table 3 . In the initial multivariate analysis using Pillai's trace, there was no main effect of group, $V=.01, F(4,115)=.35, p=.84, \eta_{\mathrm{p}}^{2}=.01$, no main effect of sex, $V=.02, F(4,115)=0.54, p=.71, \eta_{\mathrm{p}}^{2}=.02$, and no Group $\times$ Sex interaction, $V=.03, F(4,115)=1.02, p=.40, \eta_{\mathrm{p}}^{2}=.03$. Given the lack of significant multivariate effects of pre-exposure group, sex, or the Group $\times$ Sex interaction, follow-up univariate analyses were not conducted. In summary, neither the expanded preexposure treatment nor sex were associated with a significant change in performance on the Silcton tasks.

Table 3

Means and Standard Deviations on Silcton Measures for Both Pre-Exposure Groups in Experiment 2

\begin{tabular}{lcccc}
\hline $\begin{array}{c}\text { Pre-exposure } \\
\text { group }\end{array}$ & Map building & $\begin{array}{c}\text { Direction estimation } \\
\text { different routes }\end{array}$ & $\begin{array}{c}\text { Direction estimation } \\
\text { same routes }\end{array}$ & Route ordering \\
\hline $\begin{array}{l}\text { Silcton buildings } \\
\text { Males }\end{array}$ & $.48(.27)$ & $84.18(14.96)$ & $62.46(10.82)$ & $.93(.18)$ \\
Females & $.38(.27)$ & $87.17(14.18)$ & $61.35(12.78)$ & $.86(.25)$ \\
$\quad \begin{array}{l}\text { Total } \\
\text { Control buildings }\end{array}$ & $.43(.27)$ & $85.70(14.53)$ & $61.90(11.77)$ & $.89(.22)$ \\
$\quad$ Males & $.39(.26)$ & $84.85(12.63)$ & $63.54(12.77)$ & $.85(.29)$ \\
Females & $.47(.24)$ & $88.45(12.81)$ & $64.13(13.18)$ & $.85(.22)$ \\
$\quad$ Total & $.43(.25)$ & $86.56(12.74)$ & $63.82(12.86)$ & $.85(.26)$ \\
All males & $.43(.28)$ & $84.53(13.70)$ & $63.02(11.78)$ & $.89(.24)$ \\
All females & $.42(.26)$ & $86.13(13.61)$ & $62.70(12.94)$ & $.86(.24)$ \\
\hline
\end{tabular}

Note. Standard deviations are in parentheses.

${ }^{\mathrm{a}} R^{2}$ values. ${ }^{\mathrm{b}}$ Absolute error in degrees. ' ${ }^{\mathrm{c}}$ Kendall's Tau. 
As in Experiment 1, we also analyzed the Group $\times$ Sex data using Bayesian methods. For the dependent measure of differentroute direction estimation, the Bayes factor $\left(\mathrm{BF}_{01}\right)$ showed the data were 3.68:1 in favor of the null hypothesis of no effect of group, $\mathrm{BF}_{01}=3.68$, or over three times more likely to occur in a model with no group differences than one with group differences. For the effect of sex, data were 3.52:1 in favor of the null hypothesis, $\mathrm{BF}_{01}=3.52$, and for the interaction effect, the data were 3.58:1 in favor of the null hypothesis, $\mathrm{BF}_{01}=3.58$. For the other dependent measure of cognitive map accuracy, model building, the data were 5.18:1 in favor of the null hypothesis of no differences based on group, $\mathrm{BF}_{01}=5.18$, and 5.06:1 in favor of the null hypothesis versus the alternative hypothesis of sex differences, $\mathrm{BF}_{01}=5.06$. For the Group $\times$ Sex interaction, data were 1.45:1 in favor of a null model rather than a model with the interaction, $\mathrm{BF}_{01}=1.45$. For the same-route direction estimation measure, the observed data were 3.72:1 in favor of the null versus a model with group differences, $\mathrm{BF}_{01}=3.72,5.14: 1$ in favor of the null versus a model with sex differences, $\mathrm{BF}_{01}=5.14$, and 3.45:1 in favor of the null model versus a model with a Group $\times$ Sex interaction, $\mathrm{BF}_{01}=3.45$. Finally, the route ordering data were 3.55:1 in favor of the null model versus a model with an effect of group, $\mathrm{BF}_{01}=$ $3.55,4.09: 1$ in favor of the null model versus a model with an effect of sex, $\mathrm{BF}_{01}=4.09$, and 2.83:1 in favor of a null model versus a model with a Group $\times$ Sex interaction, $\mathrm{BF}_{01}=2.83$. Overall then, and most importantly with respect to the preexposure group main effect, the Bayesian analysis reveals the data provide substantial support for the null hypothesis.

Correlations between dependent measures. Next, we conducted two-tailed Pearson correlations to assess the interrelatedness of the four Silcton dependent measures in the entire sample, plus scores on the SBSOD and SOT, and sex (see Table 4). Unlike Experiment 1, the Silcton measures that are believed to rely on map-like knowledge, map building, and different-route direction estimation were not significantly correlated in this study. Instead, the two Silcton measures that are presumed to rely on route knowledge, route ordering, and same-route direction estimation showed a moderate and significant correlation. As in Experiment 1, perspective taking measured by the SOT was correlated with performance on Silcton map building and route ordering, and while it was also significantly correlated with sex, that correlation was much weaker than in Experiment 1. Also similar to Experiment 1, the routeordering measure showed a positive, although weaker, correlation with map building, indicating that better memory for the order of items along each route was associated with building a more accurate map. Finally, we confirmed that the mean error values for same-route direction estimation and different-route direction estimation were significantly different from chance $\left(90^{\circ}\right)$, same route: $t(121)=24.34$, $p<.001$, different route: $t(121)=3.14, p=.002$.

\section{Discussion}

In Experiment 2, we again found no effect of pre-exposure condition on cognitive map accuracy of Silcton, even though (1) the pre-exposure treatment was expanded to include training on both landmark identities and the order of landmarks along each main route, and 2) more participants were tested resulting in more power to detect an effect. Sex differences observed in Experiment 1 for different route direction estimation and map building were not replicated here, but the importance of perspective-taking for recalling the order of landmarks along the routes and building a map of Silcton was replicated.

\section{General Discussion}

Contrary to our predictions, we found no evidence over two experiments that pre-exposing participants to the knowledge acquired in the first two steps of Siegel and White's (1975) theory of spatial knowledge acquisition facilitated the accuracy of the cognitive maps they created of the Silcton virtual environment. Instead, findings confirmed the importance of spatial perspective taking, as measured by the SOT, for cognitive map accuracy and showed some evidence of sex differences in performance.

The failure of our pre-exposure intervention to improve performance suggests it is unlikely that weak associative memory alone is a substantial contributor to weak cognitive mapping ability. That is, a failure to encode building identities and their order along routes, separate from the spatial visualization abilities necessary to combine those routes into a cognitive map, is likely not the primary reason people show weak cognitive map accuracy in Silcton-based studies. If it were, we should see better performance in the experimental groups versus the control groups in the current studies. It seems logical that familiarizing participants with landmark buildings and the order the buildings would be encountered along routes lightened some of the mental workload involved in creating a mental representation of Silcton, but it did not drive a noticeable improvement specifically in the accuracy of the cognitive maps participants created. Therefore, our data are consistent with the idea that landmark identity and route knowledge may be necessary for an accurate cognitive map, but they are not sufficient.

Table 4

Means, Standard Deviations, and Pearson Correlations for Silcton and Non-Silcton Measures in Experiment 2

\begin{tabular}{|c|c|c|c|c|c|c|c|c|}
\hline Measure & Sex & SBSOD & SOT & $\underset{\text { building }}{\text { Map }}$ & $\begin{array}{c}\text { Route } \\
\text { ordering }\end{array}$ & $\begin{array}{l}\text { Direction estimation: } \\
\text { different routes }\end{array}$ & $M$ & $S D$ \\
\hline SBSOD & $-.22^{*}$ & - & - & - & - & - & 4.49 & 1.01 \\
\hline SOT & $.19^{*}$ & -.14 & - & - & - & - & 31.85 & 27.68 \\
\hline Map building & -.02 & .14 & $-.27^{* * *}$ & - & - & - & .43 & .26 \\
\hline Route Ordering & -.07 & -.02 & $-.30^{* * *}$ & $.20^{*}$ & - & - & .87 & .24 \\
\hline Direction estimation: different routes & .12 & -.14 & .13 & -.09 & -.11 & - & 86.13 & 13.61 \\
\hline Direction estimation: same route & -.01 & .15 & .16 & -.15 & $-.31^{* *}$ & -.08 & 62.86 & 12.31 \\
\hline
\end{tabular}

Note. $\quad N=122$. SBSOD $=$ Santa Barbara Sense of Direction Scale; SOT $=$ Spatial Orientation Test.

${ }^{*} p<.05 . \quad{ }^{* * *} p<.01$. 
Returning to the theories of spatial knowledge acquisition, the current results are more consistent with the proposal by Montello (1998) than Siegel and White (1975). Siegel and White proposed landmarks and routes as specific, isolated steps in knowledge acquisition, while Montello countered that information about landmarks and routes does not exist in isolation from knowledge of the configuration of the landmarks. The failure of our intervention to facilitate cognitive map accuracy via targeted training of landmark identities and routes is consistent with the idea that those aspects of spatial knowledge acquisition cannot be isolated from configural, or map-like, knowledge. As pointed out by Montello, both theories suggest that the progression from knowing separate routes to integrating them in a mental map is a qualitative change, and it seems that individual differences in the processing involved in that integration is a greater contributor to cognitive map accuracy than differences in encoding landmark identities and route sequences.

We can speculate that spatial visualization ability, specifically spatial perspective taking, is a key point of individual differences in spatial knowledge acquisition. Our results add to a growing body of evidence that perspective taking plays a significant role in cognitive map creation (Allen, Kirasic, Dobson, Long, \& Beck, 1996; Fields \& Shelton, 2006; Kozhevnikov et al., 2006; Schinazi et al., 2013; Weisberg et al., 2014). Precisely how perspective taking is involved in creating a cognitive map is not clear, although we conjecture that it could be important at multiple steps in the process. For instance, when travelling in the environment, participants must gradually build up a map, either as routes first as proposed by Siegel and White (1975) or possibly as a map from the beginning as proposed by Montello (1998). Perspective taking is likely involved in the online updating of position during travel by enabling a navigator to compare the perspective from remembered locations to the current perspective. Identifying where perspectives overlap would help to integrate individual sections of the map into a larger representation. It is also likely involved when retrieving the layout of the environment from a given perspective in a direction estimation or map building task. In our studies, perspective taking measured by the SOT predicted Silcton map building performance but not direction estimation, even though direction estimation test items and SOT items are of a similar "Imagine you are at X facing $\mathrm{Y}$, point to Z" construction. We hypothesize that the lack of a predictive relationship between perspective taking and direction estimation is due to the difficult challenge of imagining perspectives based only on memory in the direction estimation task used here. Comparing across studies, performance on this type of task is worse than on direction estimation tasks that place the participant in the environment, such as in Weisberg et al. (2014), although it should be noted that participants in the current study produced direction estimations that were significantly better than chance.

Our results also show a pattern of sex differences in one experiment where men outperformed women specifically on tasks assessing the accuracy of their cognitive maps of Silcton, consistent with other data (reviewed by Coluccia \& Louse, 2004). For example, men tend to outperform women on tasks such as direction estimation between landmarks (Lawton \& Morrin, 1999; Weisberg \& Newcombe, 2016; Zancada-Menendez, Sampedro-Piquero, Lopez, \& McNamara, 2016), wayfinding (Coluccia, Iosue, \& Brandimonte, 2007; Lawton, 1994; Saucier et al., 2002), and map making (Coluccia et al., Iosue, \& Brandimonte, 2007; Weisberg \&
Newcombe, 2016). Men also have been shown to outperform women on small-scale spatial ability tasks that have implications for creating cognitive maps, such as mental rotation tasks (Cook \& Saucier, 2010; Lawton, 1994; Vandenberg \& Kuse, 1978). On the other hand, women outperform men on tasks involving landmark location memory and learning from a map rather than direct experience (James \& Kimura, 1997; McGuiness \& Sparks, 1983; Montello, 1998; Silverman \& Eals, 1992). In the current study, while males outperformed females on some map-based measures, there was no sex difference on same-route direction estimation that relies on accurate route-based representations. Furthermore, it appears that part of the predictive value of sex for performance on map-based tasks is better explained by perspective taking, as could be the case in some other studies, as well.

In conclusion, the current study found no evidence that familiarizing participants with the landmarks and the order of those landmarks along routes in a new environment prior to exploring the environment enhanced their ability to create a cognitive map. Therefore, it is unlikely that the greatest contributor to variation in cognitive map accuracy in the laboratory is a lack of familiarity with the to-be-remembered landmarks. Instead, our study points to perspective-taking ability and, to some extent, sex as important contributors to cognitive map-making ability. More research is needed to further our knowledge of what underlies the individual differences seen in cognitive map accuracy and the mechanisms by which these and other factors underlie them.

\section{Résumé}

On relève d'importantes différences individuelles dans la capacité à créer une carte cognitive d'un nouvel environnement. Les études en cours ont examiné si le fait de familiariser les participants avec des points de repère cibles à apprendre (Expérience 1) ou avec des points de repère cibles en spécifiant l'ordre dans lequel ils seraient rencontrés le long des routes (Expérience 2) avant d'explorer l'environnement virtuel de Silcton pouvait améliorer les performances relativement à des tâches de mémoire spatiale de Silcton. Les participants des deux expériences ont été choisis au hasard pour être préexposés soit à l'information sur les points de repère cibles de Silcton ou à celle des points de repère de contrôle sur le campus de l'université. Dans les deux expériences, les participants ont exploré Silcton selon quatre routes imposées, puis effectué une tâche d'estimation de la direction et une tâche de production d'une carte en se basant sur leur mémoire des emplacements des points de repère cibles. Les participants ont également suivi le test d'orientation spatiale en matière de prise de perspective. Une préexposition aux points de repère de Silcton par rapport à des points de repère de contrôle n'a pas affecté les résultats des tâches basées sur Silcton dans ni l'une ni l'autre des expériences. Certaines des différences au niveau du sexe dans l'estimation de la direction ont été notées dans l'Expérience 1 mais pas dans l'expérience 2. Alors que le fait de faciliter la familiarité avec des points de repère n'a pas amélioré la précision des cartes cognitives, le sexe et la capacité à prendre une perspective ont tous les deux contribué aux différences individuelles en termes de capacité à créer une carte cognitive.

Mots-clés : cognition spatiale, navigation, carte cognitive. 


\section{References}

Allen, G. L., Kirasic, K. C., Dobson, S. H., Long, R. G., \& Beck, S. (1996). Predicting environmental learning from spatial abilities: An indirect route. Intelligence, 22, 327-355. http://dx.doi.org/10.1016/S01602896(96)90026-4

Bennett, A. T. (1996). Do animals have cognitive maps? The Journal of Experimental Biology, 199, 219-224.

Chrastil, E. R., \& Warren, W. H. (2014). From cognitive maps to cognitive graphs. PLoS ONE, 9(11), e112544. http://dx.doi.org/10.1371/journal .pone. 0112544

Coluccia, E., Iosue, G., \& Brandimonte, M. A. (2007). The relationship between map drawing and spatial orientation abilities: A study of gender differences. Journal of Environmental Psychology, 27, 135-144. http:// dx.doi.org/10.1016/j.jenvp.2006.12.005

Coluccia, E., \& Louse, G. (2004). Gender differences in spatial orientation: A review. Journal of Environmental Psychology, 24, 329-340. http:// dx.doi.org/10.1016/j.jenvp.2004.08.006

Cook, C. M., \& Saucier, D. M. (2010). Mental rotation, targeting ability and Baron-Cohen's empathizing-systemizing theory of sex differences. Personality and Individual Differences, 49, 712-716. http://dx.doi.org/ 10.1016/j.paid.2010.06.010

Faul, F., Erdfelder, E., Lang, A. G., \& Buchner, A. (2007). G*Power 3: A flexible statistical power analysis program for the social, behavioral, and biomedical sciences. Behavior Research Methods, 39, 175-191. http:// dx.doi.org/10.3758/BF03193146

Fields, A. W., \& Shelton, A. L. (2006). Individual skill differences and large-scale environmental learning. Journal of Experimental Psychology: Learning, Memory, and Cognition, 32, 506-515. http://dx.doi.org/ 10.1037/0278-7393.32.3.506

Hegarty, M., Montello, D. R., Richardson, A. E., Ishikawa, T., \& Lovelace, K. (2006). Spatial abilities at different scales: Individual differences in aptitude-test performance and spatial-layout learning. Intelligence, 34, 151-176. http://dx.doi.org/10.1016/j.intell.2005.09.005

Hegarty, M., Richardson, A. E., Montello, D. R., Lovelace, K., \& Subbiah, I. (2002). Development of a self-report measure of environmental spatial ability. Intelligence, 30, 425-447. http://dx.doi.org/10.1016/S01602896(02)00116-2

Hegarty, M., \& Waller, D. (2004). A dissociation between mental rotation and perspective-taking spatial abilities. Intelligence, 32, 175-191. http:// dx.doi.org/10.1016/j.intell.2003.12.001

Ishikawa, T., \& Montello, D. R. (2006). Spatial knowledge acquisition from direct experience in the environment: Individual differences in the development of metric knowledge and the integration of separately learned places. Cognitive Psychology, 52, 93-129. http://dx.doi.org/10 .1016/j.cogpsych.2005.08.003

James, T. W., \& Kimura, D. (1997). Sex differences in remembering the locations of objects in an array: Location-shifts versus locationexchanges. Evolution and Human Behavior, 18, 155-163. http://dx.doi .org/10.1016/S1090-5138(97)00004-4

JASP Team (2018). JASP (Version 0.9) [Computer software]. Retrieved from https://jasp-stats.org

Kozhevnikov, M., \& Hegarty, M. (2001). A dissociation between object manipulation spatial ability and spatial orientation ability. Memory \& Cognition, 29, 745-756. http://dx.doi.org/10.3758/BF03200477

Kozhevnikov, M., Motes, M. A., Rasch, B., \& Blajenkova, O. (2006). Perspective-taking vs. mental rotation transformations and how they predict spatial navigation performance. Applied Cognitive Psychology, 20, 397-417. http://dx.doi.org/10.1002/acp.1192
Lawton, C. A. (1994). Gender differences in way-finding strategies: Relationship to spatial ability and spatial anxiety. Sex Roles, 30, 765-779. http://dx.doi.org/10.1007/BF01544230

Lawton, C. A., \& Morrin, K. A. (1999). Gender differences in pointing accuracy in computer-simulated 3D mazes. Sex Roles, 40, 73-92. http:// dx.doi.org/10.1023/A:1018830401088

McGuiness, D., \& Sparks, J. (1983). Cognitive style and cognitive maps: Sex differences in representations of a familiar terrain. Journal of Mental Imagery, 7, 91-100.

Montello, D. R. (1998). A new framework for understanding the acquisition of spatial knowledge in large-scale environments. In M. J. Egenhofer \& R. G. Golledge (Eds.), Spatial and temporal reasoning in geographic information systems (pp. 143-154). New York, NY: Oxford University Press.

O'Keefe, J., \& Nadel, L. (1978). The hippocampus as a cognitive map. Oxford, England: Clarendon Press.

Saucier, D. M., Green, S. M., Leason, J., MacFadden, A., Bell, S., \& Elias, L. J. (2002). Are sex differences in navigation caused by sexually dimorphic strategies or by differences in the ability to use the strategies? Behavioral Neuroscience, 116, 403-410. http://dx.doi.org/10.1037/ 0735-7044.116.3.403

Schinazi, V. R., Nardi, D., Newcombe, N. S., Shipley, T. F., \& Epstein, R. A. (2013). Hippocampal size predicts rapid learning of a cognitive map in humans. Hippocampus, 23, 515-528. http://dx.doi.org/10.1002/ hipo. 22111

Siegel, A. W., \& White, S. H. (1975). The development of spatial representations of large-scale environments. Advances in Child Development and Behavior, 10, 9-55. http://dx.doi.org/10.1016/S00652407(08)60007-5

Silverman, I., \& Eals, M. (1992). Sex differences in spatial abilities: Evolutionary theory and data. In J. H. Barkow, L. Cosmides, \& J. Tooby (Eds.), The adapted mind: Evolutionary psychology and the generation of culture (pp. 533-549). New York, NY: Oxford University Press.

Tolman, E. C. (1948). Cognitive maps in rats and men. Psychological Review, 55, 189-208. http://dx.doi.org/10.1037/h0061626

Vandenberg, S. G., \& Kuse, A. R. (1978). Mental rotations, a group test of three-dimensional spatial visualization. Perceptual and Motor Skills, 47, 599-604. http://dx.doi.org/10.2466/pms.1978.47.2.599

Waller, D., \& Lippa, Y. (2007). Landmarks as beacons and associative cues: Their role in route learning. Memory \& Cognition, 35, 910-924. http://dx.doi.org/10.3758/BF03193465

Weisberg, S. M., \& Newcombe, N. S. (2016). How do (some) people make a cognitive map? Routes, places, and working memory. Journal of Experimental Psychology: Learning, Memory, and Cognition, 42, 768785. http://dx.doi.org/10.1037/xlm0000200

Weisberg, S. M., Schinazi, V. R., Newcombe, N. S., Shipley, T. F., \& Epstein, R. A. (2014). Variations in cognitive maps: Understanding individual differences in navigation. Journal of Experimental Psychology: Learning, Memory, and Cognition, 40, 669-682. http://dx.doi.org/ $10.1037 / \mathrm{a} 0035261$

Wolbers, T., \& Hegarty, M. (2010). What determines our navigational abilities? Trends in Cognitive Sciences, 14, 138-146. http://dx.doi.org/ 10.1016/j.tics.2010.01.001

Zancada-Menendez, C., Sampedro-Piquero, P., Lopez, L., \& McNamara, T. P. (2016). Age and gender differences in spatial perspective taking. Aging Clinical and Experimental Research, 28, 289-296. http://dx.doi .org/10.1007/s40520-015-0399-Z

Received November 24, 2017 Accepted December 15, 2018 